\title{
Care of the Elderly Symposium
}

\author{
A symposium held on 30 March 2012 at the Royal College of Physicians of Edinburgh \\ R Caslake \\ Clinical Lecturer in Old Age Medicine, Division of Applied Medicine, University of Aberdeen, Scotland, UK
}

DECLARATION OF INTERESTS No conflicts of interest declared.

\author{
Correspondence to $\mathbf{R}$ Caslake \\ Department of Medicine \\ for the Elderly, \\ Woodend Hospital, Eday Road, \\ Aberdeen ABI 5 6XS, UK \\ tel. +44 (0) I 224556789 \\ e-mail bob.caslake@abdn.ac.uk
}

\section{INTRODUCTION}

The management of chronic disease is a key part of all modern medicine and it can be a particular challenge for those caring for the frail elderly, especially when it is found in the acute setting, either incidentally or as a factor contributing to the presenting problem. This symposium covered a range of common chronic conditions that are seen routinely in general practitioner (GP) surgeries and in medical and geriatric assessment units, with the aim of helping clinicians provide confident, evidence-based and humane care to their patients.

\section{SESSION I: MANAGING PATIENTS WITH DEMENTIA IN THE ACUTE SETTING}

Professor Rowan Harwood (Consultant in Elderly Medicine, Nottingham University Hospitals NHS Trust) reminded us that the outcomes for people with cognitive impairment admitted to acute hospitals are poor, with $27 \%$ of those admitted not returning to their original residence. These people are complex and dependant but, despite these difficulties, providing better quality care is possible with appropriate leadership, skills and resources. Sube Banerjee (Professor of Mental Health and Ageing, King's College London) discussed the limited role of antidepressants and antipsychotics in dementia. Antidepressant medication appears to be no better than placebo in these patients' and antipsychotics used in people with dementia were shown to be harmful overall, resulting in around I,800 deaths a year. Medico-legal issues were then discussed by Dr Donald Lyons (Chief Executive, Mental Welfare Commission for Scotland). We were reminded that we should act according to the principles of the Adults with Incapacity (Scotland) Act 2000 , but that often we don't. ${ }^{2}$ The key principles are that when dealing with people with diminished decision making ability, our actions should benefit them, we should impose the least possible restriction on their freedom, we should take their present and past views into account and we should consult others where practicable. Doctors and nurses are often poor at documenting their assessment of a patient's capacity.

\section{SESSION 2: RESPIRATORY DISEASE}

A session on respiratory disease in the elderly began with a talk by Dr Stanley Wright (Consultant Respiratory Physician, Forth Valley) on the diagnosis and management of chronic obstructive pulmonary disease (COPD) and its impact on quality of life, which at its worst can be greater than for those with non-small cell lung cancer. The person-based approach that he advocated should be familiar to all those involved in caring for elderly patients. Professor Stephen Allen (Consultant in Elderly Medicine, Royal Bournemouth and Christchurch Hospitals NHS Foundation Trust) explained that the management of dyspnoea in people with COPD is often more complex than it initially appears, with multiple causes instead of, or in addition to, an acute exacerbation. He illustrated his message with a number of instructive cases. The risks and benefits of inhaled anticholinergic therapy were discussed by Professor Peter Calverley (Consultant in Respiratory Medicine, University Hospital, Aintree). There has been some concern about these drugs increasing the risk of sudden death on the basis of an early meta-analysis but this was not supported by a subsequent large clinical trial. ${ }^{3}$ Professor Calverley concluded that the risk/benefit ratio of these drugs was favourable but that long-acting beta agonists may be better in terms of mortality.

\section{SESSION 3: PARKINSON'S DISEASE}

The Sydney Watson Smith lecture was delivered by Professor Bastiaan Bloem (Medical Director, Parkinson Centre, Nijmegen, the Netherlands). His case studies clearly demonstrated that the involvement of allied health professionals in the care of people with Parkinson's disease (PD) can result in striking improvements to their function. An innovative professional network of physiotherapists in the Netherlands (ParkinsonNet) has been set up and has improved the quality of healthcare for people with PD while reducing costs. This was followed by a practical guide to the diagnosis of parkinsonian syndromes by Dr Carl Counsell (Reader in Neurology, University of Aberdeen). The difficulties in 
diagnosing parkinsonism and determining its specific cause were clearly illustrated by a number of clinical videos. ${ }^{4}$ Dr Douglas MacMahon (Consultant Physician, Department of Neurology, University Hospitals of Coventry and Warwickshire NHS Trust) discussed management of PD on the acute ward. ${ }^{5} \mathrm{He}$ urged us to exercise caution in diagnosing PD during an acute admission and in particular suggested that dopaminergic medication should not be started before assessment by a specialist. He also stressed caution in prescribing for people with PD, paying particular attention to medication timings and avoidance of anti-emetics and antipsychotics, which can cause worsening of parkinsonism.

\section{REFERENCES}

I Banerjee S, Hellier J, Dewey $M$ et al. Sertraline of mirtazapine for depression in dementia (HTA-SADD): a randomised, multicentre, double-blind, placebo-controlled trial. Lancet 201 I; 378:403-II. http://dx.doi.org/I0.10I6/S0I40-6736(I I)60830-I

2 Tait S, Lyons D. Starved of care [Internet]. Edinburgh: Mental Welfare Commission for Scotland; 201I [cited 2012 April 20]. Available from: http://reports.mwcscot.org.uk/web/files/MWC Mrs_V_Report.pdt

3 Tashkin DP, Celli B, Senn S et al. A 4-year trial of tiotropium in chronic obstructive pulmonary disease. N Engl J Med 2008; 359: 1543-54. http://dx.doi.org/I0.I056/NEJMoa0805800

\section{TAKE-HOME MESSAGE}

The complexity of the diagnosis and management of chronic conditions in the context of acute illness remains one of the most challenging aspects of the care of older patients. It was made clear by all of those contributing to the symposium that with thoughtful, humane and holistic care there was scope to improve the situation of people suffering from these conditions and that this should be a clear priority for all of those involved in the provision and delivery of healthcare.
4 Taylor KSM, Counsell C. Is it Parkinson's disease, and if not, what is it? Pract Neurol 2006; 6:154-65. http://dx.doi.org//0.1/36/ jnnp.2006.091835

5 Gerlach OH,Winogrodzka A, Weber WE. Clinical problems in the hospitalized Parkinson's disease patient: systematic review. Mov Disord 201 I; 26: 197-208. http://dx.doi.org/I0.1002/mds.23449 